\title{
A voz poética dos protagonistas: a (re)construção do real em La ocasión, de Juan José Saer, e em Dom Casmurro, de Machado de Assis
}

\author{
Raquel Alves Mota \\ Mestre em Estudos literários / UFMG
}

\begin{abstract}
RESUMO
Visualiza-se como Bianco, no romance La ocasión, se imiscui sua perspectiva ficcional no relato dirigido pelo anônimo narrador heterodiegético e, como em Dom Casmurro, o distanciamento entre narrador e personagem, favorece enxergar a postura poética do narrador Dom Casmurro na preocupação iterativa de formulação do relato que escreve.
\end{abstract}

\section{PALAVRAS-CHAVE}

Narrador, focalização, voz poética

A possibilidade de cotejo do romance La ocasión (1986), do escritor argentino Juan José Saer (Serodino, Santa Fe, 1937 - Paris, 2005), com o romance Dom Casmurro (1900), de Machado de Assis (1839-1908), mostrou-se produtiva, dada a semelhança da intriga central nos dois romances; isto é, a reabordagem, em La ocasión, de um provável trio amoroso. Repete-se, então, nos dois romances, a questão do possível adultério do amigo do protagonista com a esposa deste, e neles estão narrativas que priorizam o ponto de vista do protagonista, em que a diegese se constrói no mesmo período temporal: o final do século 19. As semelhanças entre os dois romances se vislumbram: no enredo, na temporalidade do enunciado-narrativo, e mesmo na performance dos respectivos protagonistas, na "contagem" de suas histórias.

Assim, o enredo de La ocasión rememora o mais conhecido romance de Machado de Assis: Dom Casmurro. Essa aproximação traz outras questões que especificam o tratamento que Saer e Machado deram ao conflito da incerteza a respeito do adultério da mulher do protagonista, ou às estruturas elaboradas pelo narrador visando privilegiar a perspectiva da 
personagem em questão. O diálogo entre essas obras se firma quando, na análise de $L a$ ocasión, observam-se convergências com Dom Casmurro. A partir dessas confluências, explicitam-se as particularidades dos romances, o que conduz ao estudo de algumas dessas especificidades narrativas. Pode-se aqui retomar que, partindo do romance de Saer, o primeiro foco de análise é a performance da voz narrativa, visando desvendar a voz poética dos protagonistas. O trabalho preludia nas confluências dos romances e se estende na análise das particularidades desses mesmos esquemas.

Observa-se, então, que os narradores dos romances se manifestam diferentemente: em Saer, o narrador é heterodiegético e, em Machado, tem-se um narrador homodiegético. Apesar da diferença estrutural, os narradores assemelham-se quanto à relação com as personagens centrais dos romances. Em La ocasión, o narrador heterodiegético aproxima-se da personagem Bianco, detendo sobre esta o ponto de vista da história. Em algumas partes, essa associação impossibilita a identificação da voz, devido ao recurso contumaz das analepses. Em Dom Casmurro, ouve-se a voz da personagem, porque quem conduz o relato é um narrador homodiegético. O protagonista narrador Dom Casmurro detém a voz e a visão do narrado, já que o ponto de vista da história provém também de sua perspectiva. Assim, cada um à sua maneira, os dois narradores, belicosamente, intervêm na plataforma do narrado, nos planos da focalização e da voz narrativa. Essa interferência dos protagonistas, ou seu domínio no relato, comprova que a nuance poética promulgada nas entrelinhas do texto advém do ponto de vista dessas personagens.

Quando Dom Casmurro propõe que escreve sua história, o modo como organiza os fatos sucedidos, demonstra um questionamento da estrutura do relato. Não somente a estrutura é problematizada, mas também a natureza do que se escreve, já que não há certeza em relação aos "acontecimentos" narrados. Bianco, em La ocasión, apesar de não ser o narrador de sua história, escamoteia essa função, quando detém o ponto de vista do texto, usurpando a voz na profusão incessante das analepses. Bianco também se serve de um espaço para difundir, com liberdade, seu ponto de vista com respeito ao rearranjo da realidade. Com o objetivo de frisar essa discussão poética empreendida pelos protagonistas de La ocasión e de Dom Casmurro, o primeiro passo é desvendar o estatuto dos seus narradores. O trabalho desenvolve-se partindo do plano do narrador, da voz enunciativa do texto e, por meio do estudo estrutural da manifestação narrativa, é possível comprovar o gesto estético que os protagonistas disseminam no relato. 
Percebe-se que, a estrutura narrativa dos romances é responsável pela liberdade concedida à personagem central ${ }^{1}$ para difundir o seu ponto de vista da história. Tomando-se La ocasión como ponto de partida, sublinha-se o estratagema empreendido por Bianco para arredar o narrador para junto de si. Intervindo, primeiramente, no ponto de vista da história, posteriormente Bianco monopoliza a ação e o desenvolvimento da narrativa. Essa ilusão narrativa, já que se trata de um narrador heterodiegético, se constrói devido ao fato de o narrador gradativamente se eclipsar em benefício da ação do protagonista. Os recursos das analepses beneficiam a indefinição de qual voz se ouve no texto. Algumas analepses se manifestam como monólogo interior ou segundo o ponto de vista da personagem; quanto a elas, o conflito se manifesta quando não se distingue a "voz" da personagem da voz do narrador, devido à indefinição entre monólogo interior e discurso indireto livre. Concorrendo para essa indefinição, as modalizações ${ }^{2}$ pulverizam a certeza de quem seja a porta-voz do relato. Dessa forma, Bianco estende seu controle ao conjunto narrado, o que faz com que o texto produza a sensação de que é essa personagem que o leitor ouve; e esse esquema narrativo esclarece como a personagem emerge como ponto de vista e voz do relato.

Essa relação entre narrador e personagem é importante para que se visualize o espaço que ela tem para difundir sua perspectiva em relação ao manuseio do real. Esse viés poético da personagem comunga a perspectiva como o narrador estrutura o relato. A personagem Bianco não somente é o objeto do relato, como também entabula a própria trama, na qual projeta sua pessoa. Bianco estrutura a sua própria história, na medida em que encabeça as analepses, ou a organização dos acontecimentos. Ademais, sua influência se faz sentir, também, no plano do conteúdo narrado, quando provoca inflexões no curso de sua história, com suas suspeitas desenvolvidas, a priori, aos acontecimentos que poderiam embasar tal desconfiança. ${ }^{3}$ A aquiescência entre o narrador e a personagem desvenda outra relação: o posicionamento de Bianco em relação às "forças materiais" relembra o ponto de vista poético defendido por Saer em seus ensaios críticos. O romance postula a discussão ficcional saeriana da insidiosa divisão entre o real e o ficcional, como deslinda Premat:

\footnotetext{
${ }^{1}$ Neste ensaio, utiliza-se o termo protagonista para designar a personagem central do romance: Bianco, em La ocasión, e Dom Casmurro (narrador-personagem), em Dom Casmurro.

${ }^{2} \mathrm{O}$ crítico define, nestes termos, esse recurso: "Isso que a lingüística chama pomposamente de 'modalização' nada mais é que o estudado distanciamento de um enunciador relativamente à matéria narrada." (RIBEIRO. Um canário cheio de idéias, p. 99-108.)

${ }^{3}$ Bianco, anteriormente à cena capital do romance - o encontro do protagonista com Gina e Garay sozinhos em sua casa, em uma cena que evade sensualidade - já promovia maneiras de unir o seu amigo à sua esposa, como uma forma de provar as suspeitas que ele ali percebia. Com isso, Bianco torna-se o mentor de seu próprio dilema, ou do enredo da história que protagoniza.
} 
Es sabido que en la obra la noción de acontecimiento, paralelamente a la de percepción, condensa la puesta en duda formal de los límites del acto literario y funciona al mismo tiempo como motor de una ficcionalización autorreferencial. Saer reconoce sus interrogantes al respecto; no sólo sobre la posibilidad de expresar con palabras cualquier hecho o recuerdo, por nimio que sea, sino sobre la eventualidad misma de aprehender y conocer cualquier acontecimiento. ${ }^{4}$

Em Dom Casmurro, não há dificuldade para se perceber a relação entre narrador e personagem, já que a narrativa é construída segundo a perspectiva do protagonista Dom Casmurro, que narra e escreve sua história. Na discussão sobre este narrador, o ponto nevrálgico é distinguir o narrador Dom Casmurro da personagem Bentinho, ou estabelecer os pontos específicos de atuação dessas duas pessoas; ou seja: a análise, em certa medida, é desenvolvida a contrapelo daquela da qual foi alvo o romance de Saer. Em La ocasión, a aproximação entre o protagonista Bianco e o narrador anônimo, que se procurou mostrar, justifica-se pelo seguinte escopo: delinear o teor poético do discurso de Bianco, ou seu vínculo com a perspectiva do narrador, e a de Saer, em um plano superior. A análise da diferença de postura dos narradores, nos romances, de Saer e de Machado, visa um mesmo fim: o aspecto poético do discurso dos protagonistas. Com o objetivo de atestar a "voz" poética de Bianco, é necessário seguir as estruturas narrativas que favorecem a manifestação dessa personagem no relato.

Retornando ao romance de Machado, no enfoque do narrador homodiegético de Dom Casmurro, o objetivo é demonstrar a disjunção entre Bentinho e Dom Casmurro; ou seja: deslindar como o narrador adquire independência para contar a história de seu duplo, de Bentinho. Esse distanciamento entre o protagonista do romance e o da narrativa legitima a tese de que o primeiro se encontra "fora" da história que narra, estando, apto a expedir juízos sobre as personagens e sobre o relato, já que também se apresenta como escritor da história, como arquiteto da narrativa. Dom Casmurro inicia a sua história contando, nos primeiros dois capítulos, as peripécias que o conduziram a registrar sua autobiografia. Esses capítulos iniciais também revelam as estratégias utilizadas na confecção do relato como um todo. Esse nuance poético, porém, não se reduz a esses primeiros capítulos, tendo em vista que a postura do narrador, o seu distanciamento dos acontecimentos que conta, privilegia o aspecto

\footnotetext{
4 “É sabido que, na obra, a noção de acontecimento, paralelamente à de percepção, condensa a questão da incerteza formal dos limites do ato literário e funciona, ao mesmo tempo, como motor de uma ficcionalização autorreferencial. Saer reconhece seus interrogantes a respeito; não somente sobre a possibilidade de expressar, com palavras, qualquer fato ou recordação, por nímio que seja, mas também sobre a eventualidade de apreender e conhecer qualquer acontecimento." (PREMAT. La dicha de Saturno: escritura y melancolía en la obra de Juan José Saer, p. 364, tradução nossa.)
} 
judicativo do seu relato, ou seu iterativo movimento exegético. A liberdade que Dom Casmurro tem de, externamente, julgar a história que escreve transforma a voz narrativa em voz poética por meio da exotopia do narrador em relação à personagem. $\mathrm{O}$ narrador homodiegético de Dom Casmurro apresenta nuances de um narrador heterodiegético, ou seja, aquele que paira sobre os acontecimentos narrados, com amplo domínio sobre o todo do acontecimento. A performance do narrador se sumariza nos seguintes termos: ele se encontra por detrás da história, bem como de todas as outras personagens, e com a personagem que narra e escreve o relato, proporcionando a si mesmo amplos poderes de estruturar os acontecimentos narrados.

Nesse intercalar entre os dois romances, tem-se que, em La ocasión, o aspecto poético do texto insinua-se por meio da perspectiva de Bianco na existência de seus poderes místicos. $\mathrm{Na}$ confluência da voz narrativa do narrador heterodiegético e dos supostos monólogos interiores de Bianco, ou de sua projeção nas analepses, nasce essa junção de vozes que possibilita que Bianco também ali se revele. Somados a isso os poderes que Bianco diz ter, ou, mais nitidamente, a teoria que subjaz à manifestação dos seus supostos poderes, retoma a perspectiva do narrador anônimo com respeito a seu relato e, em um grau superior, retomam os pressupostos ficcionais de Saer, defendidos em seus ensaios. ${ }^{5}$ A voz poética de Bianco se revela "aos saltinhos", e, progressivamente, essa personagem toma conta do relato. $\mathrm{O}$ protagonista tem liberdade de expor a descrença em uma realidade absoluta, desvinculada da subjetividade do observador; ou melhor, o narrador, primeiramente, representa esse ponto de vista que, posteriormente, é acolhido pelo protagonista por meio da crença na prevalência da força do espírito sobre a matéria.

A relação estreita entre a voz do narrador anônimo e a do protagonista turva a empreitada de se estabelecer uma linha divisória nítida entre essas vozes e a perspectiva poética que elas representam. Quando o narrador esbarra na impossibilidade de apreender, por meio do relato, o espaço físico que envolve a personagem, o ponto de vista dessa descrição emerge como provindo dessa mesma personagem; ou seja, ela é responsável pela incredulidade no relato descritivo. Os poderes místicos que Bianco diz ter somente reforçam a

\footnotetext{
5 SAER, no ensaio homônimo do livro El concepto de ficción (1997), defende que realidade e imaginação seriam os elementos que comporiam o campo do ficcional, em que o segundo elemento seria o responsável pelo alargamento do campo de ação do primeiro; ou melhor: construindo-se na base de uma além-realidade, a imaginação (falso) teria a função de, paradoxalmente, aumentar a credibilidade do próprio relato ficcional.

${ }^{6}$ Termo utilizado pelo narrador Dom Casmurro, em relação às atitudes de Capitu, para angariar a confiança de Bentinho.
} 
ideologia que o narrador injeta no relato: a capacidade de controlar a matéria estende-se até a crença no domínio da ação de seus comparsas, o que faz com que Bianco urda o próprio dilema do romance. Bianco acreditava que tinha os dons de "(...) leer los pensamientos ajenos, desplazar objetos a distancia por concentración mental, modificar la forma y la sustancia íntima de los metales por el simple contacto de sus dedos". 7 Apesar de não demonstrar concretamente seus poderes, Bianco acredita na eficácia deles; crê dominar o físico por meio de sua mente e, assim, enreda a sua própria história. Bianco estabelece relação com o narrador e, mais profundamente, com o escritor Saer, posto que o protagonista também favorece condições para que a trama se firme.

A partir disso, é possível defender que o veio poético de Bianco procede dos mecanismos ficcionais da estética saeriana. A relação de Bianco com Saer se projeta no momento em que o primeiro se aproxima do narrador, usurpando sua voz, e prossegue no conluio criativo da personagem com o escritor. Os poderes místicos de Bianco o fazem projetar, juntamente com Saer, "a ocasião" necessária para que surja a cena da qual nasce o seu dilema, a dúvida acerca do adultério: o encontro de Gina e Garay López sozinhos. Assim, Bianco se junta à estética saeriana da crença no encontradiço entre realidade e fícção, ou na descrença em uma realidade desvinculada da percepção. Bianco, como Saer, acredita na aproximação entre verdade e ficção, em que esses dois vetores se consolidam em acordo com a subjetividade do observador. O projeto de Bianco é confrontado, no romance, com o da personagem Waldo, que também apresenta uma forma poética: prolepses anunciativas em dísticos octossílabos. A forma hermética do discurso de Waldo apresenta um conteúdo também fechado, já que se trata de uma previsão cabalística do destino do espectador. A crença de Bianco de poder transformar a matéria se debate contra as prolepses anunciativas de Waldo, que prevê um futuro inevitável. A disjunção dos ideais poéticos das personagens postula a aquiescência do ponto de vista de Bianco com a perspectiva saeriana da construção poética, já que, como Saer o faz, Bianco rechaça uma realidade desvinculada do indivíduo.

Em Dom Casmurro, no mesmo objetivo de visualizar a ação poética do protagonista, o trabalho se projeta no escopo de deslindar a posição estética de Dom Casmurro com relação à história de Bentinho. O primeiro passo consiste em centralizar a ação narrativa nas mãos do narrador Dom Casmurro. Após essa disjunção dos personagens do romance, o outro passo relevante é grifar os momentos poéticos da escrita de Dom Casmurro. Este, como Brás

\footnotetext{
7 “(...) ler os pensamentos dos outros, deslocar os objetos a distância, pelo poder mental, modificar a forma e a estrutura interna dos metais, por meio do mero contato de seus dedos." (SAER. La ocasión, p. 12, tradução nossa.)
} 
Cubas, ${ }^{8}$ narra e escreve sua história, sendo que, em Dom Casmurro, o diferencial é a ênfase que o narrador deposita na estruturação dos acontecimentos narrados. A aparente diacronia eclipsa as recorrentes analepses que estruturam o relato; ou melhor, o jogo entre os fatos pretéritos possibilita que o narrador pulverize sua ação de encadear o relato, com o propósito de enfatizar os fatos que mais lhe aprazem, obliterando aqueles prejudiciais àquilo que ele defende na narrativa: a culpabilidade de Capitu. Desprestigiando a diacronia, ao mesmo tempo em que projeta o texto nessa esteira, Dom Casmurro escamoteia o objetivo da escrita.

No romance, o narrador Dom Casmurro, que também se apresenta nas funções de personagem e escritor do relato fictício, exibe-se, primordialmente, na função exegética; ou seja, coloca-se distante dos acontecimentos da história que narra. Dessa forma, o narrador tem liberdade para estruturar os capítulos, dosando o conteúdo que é narrado, já que discorre sobre um passado que conhece segundo a sua perspectiva. Como forma de distinguir a voz poética do narrador, desvincula-se a ação de Dom Casmurro da ação da personagem da história, Bentinho, utilizando-se o conceito bakhtiniano de exotopia. Esse conceito teórico, porém, se valida, na análise do romance, somente após averiguadas as posições dessas duas personagens na trama.

A postura de Bentinho é contrastada com a de Dom Casmurro, o que implica o enfoque da "metamorfose" ocorrida entre essas duas personagens. Uma questão polêmica, já que a maioria dos críticos $^{9}$ defende que Bentinho apresentava atitudes "casmurras", mesmo antes de se assumir como Dom Casmurro. Tencionando resolver esse conflito, no afã de defender a tese de que Bentinho se revela como Dom Casmurro, em um momento específico da trama, a tarefa é contrastar a postura de Bentinho com a de seus comparsas: Capitu, Escobar e Ezequiel. A ingenuidade de Bentinho eclode, principalmente, na sua incapacidade de "meter os olhos para dentro de si mesmo", em atitude crítica com respeito aos seus próprios conflitos. Assim que Bentinho se transmuta em Casmurro, há um deslocamento, em cento e oitenta graus, da atitude ingênua: Dom Casmurro se torna incrédulo, com respeito a tudo e a todos; ou seja: Bentinho e Dom Casmurro representam atitudes opostas, antípodas de procedimento, que, em seus comparsas, encontram-se em interlocução permanente. Esses

\footnotetext{
${ }^{8}$ Narrador de Memórias póstumas de Brás Cubas (1881).

${ }^{9}$ A autora questiona a possibilidade de dissociar completamente Dom Casmurro de Bentinho, tendo em vista que, o livro tomado com o nome do primeiro, Dom Casmurro, conflui as duas pessoas dentro do objeto estético: "Ainda que Bentinho esteja dentro de Dom Casmurro, 'como a fruta dentro da casca' (cap. CXLVIII), qualquer técnica que empregarmos para separar um do outro será malfadada, pois é imputado ao sintagma nominal - Dom Casmurro - não somente o homem, mas, substancialmente, o livro." (MONTEIRO. Dom Casmurro: escritura e discurso: ensaio em literatura e psicanálise, p. 96.)
} 
resultados evidenciam como se mostra proveitosa a discussão bakhtiniana do conceito de exotopia, na medida em que, desvinculado Bentinho de Dom Casmurro, o passo seguinte é deslindar o gesto estético deste último.

O ponto teórico que sustenta a análise de Dom Casmurro se concentra em Bakhtin, ${ }^{10}$ no seu conceito de exotopia, que enfoca a relação estética do autor com o herói. Dom Casmurro, como autor ficcional de sua autobiografia, mantém um distanciamento proposital em relação à personagem Bentinho. Verificadas as diferenças entre essas duas personagens, a ingenuidade de Bentinho em comparação com a criticidade de Dom Casmurro, o prosseguimento da análise é destacar a posição estética que Dom Casmurro reserva à sua escrita. Segundo Bakhtin, ${ }^{11}$ há sempre um deslocamento entre o autor e a personagem da história, ou, ainda, o gesto estético do primeiro apenas se consolida se observado esse posicionamento.

No tocante à escrita autobiográfica, como no caso da de Dom Casmurro, o distanciamento também se revela. $\mathrm{O}$ autor se torna outro, para que possa circundar e formalizar a história narrada. O ponto conflitante do conceito de exotopia, que poderia necrosar a análise, seria o monologismo. O prosseguimento da discussão exige que se estabeleça a noção exotopia desvencilhada do monologismo. Em Dom Casmurro, há uma conjunção de vozes que escapam ao discurso que o narrador quer impor. Mesmo que se defenda que o romance é narrado apenas pela já embrutecida personagem Dom Casmurro, há uma efusão de outras perspectivas que eclodem nesse relato. A exotopia, ou o distanciamento entre o autor fictício e a personagem Bentinho, serve para balizar a tese de que é por meio desse autor-personagem que Machado discute uma teoria do relato ficcional. Os críticos machadianos defendem a justaposição da discussão poética em seus romances, alguns também percebem que, em Dom Casmurro, se prioriza essa metaliteratura. Machado utiliza seu escritor-personagem para percorrer o veio teórico utilizado na confecção desse romance e, assim, discute parâmetros que facilitam a compreensão de toda a sua obra literária. Isto porque Dom Casmurro fundamenta uma discussão poética que subsidia a análise dos outros romances machadianos. A interlocução entre os romances é perceptível, já que se defende que a personagem Dom Casmurro representa a criticidade da personagem Brás Cubas e que Bentinho retoma a ingenuidade da personagem Rubião, de Quincas Borba. Machado elabora,

\footnotetext{
${ }^{10}$ BAKHTIN. Estética da criação verbal.

${ }^{11}$ BAKHTIN. Estética da criação verbal.
} 
em Dom Casmurro, uma teoria poética que atravessa as barreiras do romance, retornando com pressupostos já alcançados na estética dos romances anteriores.

Retomando La ocasión, a voz poética do protagonista é vislumbrada por meio da associação, que se fez neste trabalho, dos poderes, que Bianco dizia possuir, com a visão estética saeriana. Bianco, defendendo, primordialmente, o controle do real, ou a formatação incessante do espaço em que se encontrava inserido, acreditava que geria os elementos que o circundavam. Os parâmetros dessa discussão do protagonista trouxeram os atributos ficcionais defendidos por Saer para a urdidura do texto ficcional. A discussão teórica aqui se sustenta a partir do encontro dos textos ensaísticos do escritor e, conjugados a esses, no objetivo de conceituar o termo ficção, recorreu-se ao teórico da estética do efeito: Wolfgang Iser. Devido à enorme quantidade de ensaios publicados por Saer, a ênfase recaiu no magistral "El concepto de ficción". ${ }^{12}$ Neste, Saer estrutura os mecanismos da escrita ficcional e os elementos nela inseridos. Primeiramente, Saer rechaça a divisão comumente estabelecida entre ficção e verdade. Defendendo a interação dessas duas vertentes, mesmo em uma escrita que se nomeie como não ficção, Saer postula um posicionamento, que retoma pontos defendidos por Iser em relação ao advento ficcional. A escrita ficcional, para Saer, constrói-se por meio da confluência do empírico com o imaginário. Iser aduz os três atos que consolidam o ficcional, a saber: seleção, combinação e autodesnudamento. O cotejamento da posição ficcional, de Saer e de Iser, conflui-se nos conceitos de "antropologia especulativa""13 e "antropologia literária", ${ }^{14}$ presentes, respectivamente, nas obras desses autores. Ambos os conceitos privilegiam a relação do homem como o mundo, postulando a peculiaridade do texto literário. É por meio dessa relação que se desvencilham os horizontes comedidos no objeto referencial e, assim, se alcança a liberdade que ultrapassa os conceitos de realidade e ficção.

Depois de revistos os tópicos centrais do cotejo de La ocasión com Dom Casmurro, aqui se inicia a conjunção da análise desenvolvida, ou os pontos de contato que se pode estabelecer entre os dois romances. Primeiramente, essa homologia se inicia com a tese do trabalho: a discussão poética empreendida por Saer e por Machado por meio dos protagonistas Bianco e Dom Casmurro, respectivamente. Começando a análise pelo enunciador, o primeiro

\footnotetext{
${ }^{12}$ SAER. El concepto de ficción.

${ }^{13}$ Neste termo se sumariza "o conceito de ficção" de SAER. El concepto de ficción.

${ }^{14}$ ISER. Teoria da ficção: indagações à obra de Wolfgang Iser, p. 147-178. O teórico defende que as ficções literárias decompõem e recompõem as organizações existentes fora do texto - via seleção e combinação -, por meio de uma forma própria, altamente livre.
} 
passo foi percorrer a performance do narrador, enfatizando como o protagonista estabelece uma relação estreita com esse enunciador. Após verificada a correlação entre essas duas pessoas, foi possível verificar o gesto poético dos protagonistas, a partir desse espaço aberto para professar seus ideais poéticos. Os outros pontos convergentes entre os dois romances se encontram nessa discussão acerca da poética empreendida pelos protagonistas. Entre estes, tem-se as relações que Bianco e Dom Casmurro estabelecem com o real, ou o jogo estabelecido pelos protagonistas entre o fato narrado (aquilo que, de fato, sucedeu) e a formalização dessa realidade na narrativa. Em La ocasión, o entroncamento entre real e representação se define por meio das tentativas incessantes de descrever o espaço, e as descrições funcionam como um mecanismo de preenchimento dos contornos da realidade. No afã de esgotar os limites do objeto, a própria descrição sucumbe o objeto, na medida em que lhe confere ares de irrealidade. Para Bianco, a relação entre o real e o ficcional se resolve nos seguintes termos: a descrição quase toca o real, mas se revela como representação. Intensificando essa relação, o próprio fato real se consolida mediante atributos de coisa representada; ou seja, os próprios movimentos corriqueiros das personagens são vistos na perspectiva de gestos consolidados, mediante uma autoconsciência, como um movimento estético. Bianco, retomando os pressupostos da estética saeriana, discute o espaço conjugado entre o real e o ficcional, aproximando esses dois termos ao extremo. Os fatos concretos se projetam como movimento estético, ou as engrenagens de ambos se vislumbram sob a mesma perspectiva.

Em Dom Casmurro, esse movimento é opositivo, quando comparado com o de La ocasión. Em ambos os romances, todavia, observa-se essa mesma discussão entre o real (ou aquilo que se quer mostrar como real) e a representação desses fatos ditos reais. Quando o narrador Dom Casmurro se propõe a relatar a sua história já finda, sua proposta consiste em reproduzir esse pretérito, injetando-lhe vida. O fato passado, o real, advém por meio da representação do acontecido. O interessante, contudo, é que Dom Casmurro narra os fatos de tal forma, conjugando-os com elementos poéticos, que o relato beira o ficcional, ou mais concretamente, o teatral. O gesto narrativo de Dom Casmurro pode ser resumido nos seguintes termos: o relato é tão teatral, ou poético, que parece que não é real; ou seja, mesmo que o narrador, reiteradamente, afirme que narra o acontecido, o fato pretérito, seu relato adquire relances de uma obra teatral: uma tragédia. ${ }^{15}$ Esse aspecto se faz sentir mediante o uso

\footnotetext{
${ }^{15}$ No cap. CXXXVIII, Dom Casmurro rejeita que sua narrativa seja assimilada como uma peça teatral: "QUANDO LEVANTEI a cabeça, dei com a figura de Capitu diante de mim. Eis aí outro lance, que parecerá de teatro, e é tão natural como o primeiro.” (MACHADO. Dom Casmurro, p. 937.)
} 
de técnicas de estruturação do relato conjugadas com a interlocução permanente com o gênero ${ }^{16}$ teatro. Essa relação do relato com obras ficcionais retoma o aspecto poético aqui defendido. Dessa forma, mesmo intitulando o relato como uma forma de reviver o já vivido, Dom Casmurro não consegue se distanciar do aspecto poético. Essa nuança poética é perceptível, sobretudo, quando o narrador recorre ao leitor, afirmando que o que "conta" é o que de fato aconteceu e não uma peça dramática, como se apresenta.

Retomando o paralelo com o romance de Saer, percebe-se que, enquanto Bianco não acredita na materialidade dos fatos, percebendo tudo como uma grande representação, Dom Casmurro busca retratar os fatos e descobre nesse movimento um aspecto ficcional. Aproximando-se essas duas posturas, é possível perceber que, nos dois romances, o real e o ficcional encontram-se imbricados. Bianco, inescrupulosamente, condiciona os acontecimentos de sua história ou reduz a nada a distância entre o real e o fíctício. Dom Casmurro, por sua vez, gerindo a sua memória falha, recondiciona o seu passado, visando provar a culpa de sua mulher. No emaranhado desse pretérito, até mesmo o narrador suspeita que, dada a sincronia dos acontecimentos, o leitor possa recusar o relato como verdadeiro; disto a necessidade iterativa de asseverar o narrado.

Em função disso, a relação pujante dos protagonistas com o fato e a elucubração desse acontecimento faz com que a discussão se volte para o próprio texto, ou que abandone o referente e se estabeleça na estruturação da própria linguagem. Em Saer, como aponta Premat, ${ }^{17}$ a relação com o espaço se condiciona às extravagâncias da percepção subjetiva. Esse encontro com a realidade produz forças virulentas que recondicionam o indivíduo para os limites do texto e é nesse momento que se estabelece o "autotematismo" ou a discussão das estruturas poéticas dentro do limite ficcional. Essa inaptidão com o referente produz uma força centrípeta que retoma o controle da discussão ou reconduz o indivíduo e os questionamentos ao entorno ficcional. A prontidão do protagonista Bianco em discutir os parâmetros da escrita ficcional saeriana encontra legitimidade nesse esquema, posto que a voz do narrador se manifesta imbuída da perspectiva do protagonista quanto ao manuseio do real, o que produz a discussão da "poética do real" nos limites do narrado. Então, a discussão poética do real é uma das formas de se visualizar a relação que o texto saeriano estabelece com o referente e com a própria linguagem, já que o encontro com a realidade impossibilita a

\footnotetext{
${ }^{16}$ Caldwell, em O Otelo brasileiro de Machado de Assis, estabelece uma relação entre o romance de Machado Dom Casmurro e as tragédias de Shakespeare, como Otelo e Romeu e Julieta.

${ }^{17}$ PREMAT. La dicha de Saturno: escritura y melancolía en la obra de Juan José Saer.
} 
descrição, gerando o retorno ao próprio texto ou a formalização dessa poética nos limites ficcionais, porque

[u]na poética de lo real entonces, que pareciera, en última instancia, sólo hablar de sí misma, de las condiciones y límites del surgimiento del texto, a partir de una autonomía solipsista de la obra literaria; o una poética de lo real que ocultaría un fondo pulsional virulento, dispuesto siempre a irrumpir y desdibujar las coordenadas de esa misma realidad $(\ldots)^{18}$

Em Dom Casmurro, os limites do real também são inventariados pelo discurso do narrador. O jogo entre o que se sucedeu na perspectiva de Dom Casmurro, em confronto com o que pode ter ocorrido, exige, desse narrador, uma formalização apropriada, para que seu ponto de vista conquiste o leitor. Contudo, posto que não há certezas quanto ao ocorrido, as fissuras do discurso se revelam nas muitas vozes que emergem da voz narrativa. Nesse romance de Machado, a tentativa de absorver o real, por meio das reminiscências do enunciador, acaba sujeitando-se às técnicas poéticas empreendidas para angariar a recepção. Dom Casmurro, disposto a enxergar apenas a sua perspectiva do ocorrido, reduz o todo a esse ponto de vista, preenchendo o espaço restante com a estruturação ficcional desse ocorrido. Dom Casmurro privilegia a formalização do seu relato: o significante e a estruturação desse significante. Então, com o objetivo de eclipsar a parcialidade do seu relato, o narrador lançase ao poético, ou justapõe à sua verdade uma interlocução com obras literárias.

Disto se percebe algumas diferenças entre o rearranjo do real em La ocasión e em Dom Casmurro. No primeiro, as tentativas de apreender o real se evanescem quando o protagonista defende a proximidade do real com a representação desse real. Há, aqui, uma confluência entre realidade e representação. Em Dom Casmurro, o narrador defende o relato como uma inexorável verdade, mas projeta o texto em inteira relação com obras literárias. Em certa medida, pode-se perceber a mesma proposta de turvejar o espaço entre real e representação ou de aproximar esses dois topos, já que “[o] discurso remete ao Real, mas a impossibilidade de apreendê-lo faz irromper este Real, através dos lapsos de linguagem. Onde a linguagem fal(h)a emergirá o Real." ${ }^{19}$ Assim, em ambos os romances, a relação com o referente esgota esse real (dada a impossibilidade de apreendê-lo), o que reconduz a discussão para a formalização do próprio relato. Dom Casmurro, incapaz de reescrever o vivido, ajusta

18 “[u]ma poética do real que, então, parecesse, em última instância, somente falar de si mesma, das condições e dos limites do surgimento do texto, a partir de uma autonomia solipsista da obra literária; ou uma poética do real que ocultaria um fundo pulsional virulento, disposto, sempre, a irromper e tornar imprecisas as coordenadas dessa mesma realidade..." (PREMAT. La dicha de Saturno, p. 20, tradução nossa.)

${ }^{19}$ MONTEIRO. Dom Casmurro: escritura e discurso: ensaio em literatura e psicanálise, p. 47. 
esse real por meio de formalizações literárias já conhecidas ou reveste o seu discurso de atributos estéticos. Bianco, por sua vez, ultrapassa os limites de mera personagem narrada e se coloca conjuntamente ao narrador, promulgando a estética saeriana do conflitante espaço entre realidade e fíç̧ão. O tema da incapacidade de se circunscrever o real é recorrente nos romances, já que os relatos dos protagonistas se esgotam na incapacidade de delinear o fato passado, devido às fraturas do desconhecido. Esses espaços em branco resgatam o texto da tentativa infrutífera de reproduzir o real, reenviando a discussão para o interior do próprio texto, na reconstrução pela linguagem dessa realidade já esvaída; ou seja, em ambos os projetos, o teor poético subleva-se contra as outras motivações primeiras.

\title{
RESUMEN
}

Se investiga como Bianco, en La ocasión, inmiscuye su perspectiva ficcional en el relato dirigido por el anónimo narrador heterodiegético y, como en Dom Casmurro, el distanciamiento entre narrador y personaje, favorece observar la postura poética del narrador Dom Casmurro, en su búsqueda iterativa de formulación del relato que escribe.

\author{
Palabras-llaves
}

Narrador, focalización, voz poética

\section{REFERÊNCIAS}

ASSIS. Machado de. Memórias póstumas de Brás Cubas. In: Obra completa. COUTINHO, Afrânio (Org.). Rio de Janeiro: Nova Aguilar, 1997a. v. 1. p. 511-639.

ASSIS. Machado de. Quincas Borba. In: Obra completa. COUTINHO, Afrânio (Org.). Rio de Janeiro: Nova Aguilar, 1997b. v. 1. p. 641-806.

ASSIS. Machado de. Dom Casmurro. In: Obra completa. COUTINHO, Afrânio (Org.). Rio de Janeiro: Nova Aguilar, 1997c. v. 1. p.807-944.

ASSIS. Machado de. O espelho. In: Papéis avulsos. Obra completa. COUTINHO, Afrânio (Org.). Rio de Janeiro: Nova Aguilar, 1997d. v. 2. p. 345-352.

BAKHTIN, Mikhail. Problemas da poética de Dostoievski. Trad. Paulo Bezerra. Rio de Janeiro: Forense-Universitária, 1981.

BAKHTIN, Mikhail. Estética da criação verbal. Trad. Maria Ermantina Galvão Gomes Pereira. São Paulo: Martins Fontes, 1992.

CALDWELL, Helen. O Otelo brasileiro de Machado de Assis. São Paulo: Ateliê, 2002. 
FUKS, Julián Miguel Barbero. Juan José Saer e o paradoxo necessário: ou Uma poética da (i)mobilidade em Nadie nada nunca. Orientadora: Ana Cecília Arias Olmos. 2009. Dissertação (Mestrado em Letras) - Faculdade de Filosofia, Letras e Ciências Humanas, Universidade de São Paulo, São Paulo, 2009.

GENETTE, Gérard. Discurso da narrativa. 3. ed. Trad. Fernando Cabral Martins. Lisboa: Vega, 1995.

GLEDSON, John. Machado de Assis: impostura e realismo. São Paulo: Cia. das Letras, 1991.

ISER, Wolfgang. Situação do problema. In: O ato de leitura: uma teoria do efeito estético. São Paulo: Ed. 34, 1996a. v. 1. p. 21-98.

ISER, Wolfgang. Prefácio. In: . O fictício e o imaginário. Rio de Janeiro: UERJ, $1996 \mathrm{~b}$. p. 7-12.

ISER, Wolfgang. O que é antropologia literária? In: CASTRO ROCHA, João Cezar de (Org.). Teoria da ficção: indagações à obra de Wolfgang Iser. Rio de Janeiro: UERJ, 1999. p. 147178.

ISER, Wolfgang. Os atos de fingir ou o que é fictício no texto ficcional. In: COSTA LIMA, Luiz. Teoria da literatura em suas fontes. 2. ed. Rio de Janeiro: Francisco Alves, 2002. v. 2. p. 955-987.

LINS BRANDÃO, Jacyntho. A invenção do romance. Brasília: Editora Universidade de Brasília, 2005.

MONTEIRO, Valério Jacó. Dom Casmurro: escritura e discurso: ensaio em literatura e psicanálise. São Paulo: Hackers Editores; Cespuc, 1997.

POUILLON, Jean. O tempo no romance. Trad. Heloysa de Lima Dantas. São Paulo: Cultrix; Ed. da Universidade de São Paulo, 1974.

PREMAT, Julio. La dicha de Saturno: escritura y melancolía en la obra de Juan José Saer. Rosario: Beatriz Viterbo, 2002.

RAVETTI, Graciela. Nem pedra na pedra, nem ar no ar: reflexões sobre literatura latinoamericana. Belo Horizonte: Editora UFMG, 2011.

RIBEIRO, Luís Filipe. Um canário cheio de idéias. In: SECHIN, Antônio Carlos; BASTOS, Dau; JOBIM, José Luís (Org.). Machado de Assis: novas perspectivas sobre a obra e autor, no centenário de sua morte. De Letras. Niterói, RJ: Ed. UFF, 2008. p. 99-108.

SAER, Juan José. El concepto de ficción. Buenos Aires: Espasa Calpe, 1997.

SAER, Juan José. La narración-objeto. Buenos Aires: Seix Barral, 1999.

SAER, Juan José La ocasión. 2. ed. Buenos Aires: Seix Barral, 2003.

SARAIVA, Juracy Assmann. O estatuto do narrador. In: O circuito das memórias em Machado de Assis. São Paulo: Editora da Universidade de São Paulo; São Leopoldo, RS: Editora Unisinos, 1993. p. 11-40. (Campi, 14)

SCHWARZ, Roberto. Um mestre na periferia do capitalismo: Machado de Assis. 4. ed. São Paulo: Duas Cidades; Ed. 34, 2000.

TODOROV, Tzvetan. Literatura e significação. Trad. António José Massano. Lisboa: Assírio \& Alvim, 1967.

TODOROV, Tzvetan. As estruturas narrativas. Trad. Leyla Perrone-Moisés. 2. ed. São Paulo: Perspectiva, 1970. 